\title{
Correlation of shift work and waist circumference, body mass index, chronotype and depressive symptoms
}

\author{
Correlação entre trabalho de turno e circunferência abdominal, \\ índice de massa corporal, cronotipo e sintomas depressivos
}

Luciana da Conceição Antunes ${ }^{1}$, Manoela Neves da Jornada', Letícia Ramalho', Maria Paz Loayza Hidalgo ${ }^{1,2}$

${ }^{1}$ Post-Graduation Program in Medical Sciences, School of Medicine, Universidade Federal do Rio Grande do Sul (UFRGS), Porto Alegre, Brazil ${ }^{2}$ Human Chronobiology Program of Clinical Hospital of Porto Alegre (HCPA), Psychiatric and Legal Medicine Department, Medical School, UFRGS, Porto Alegre, RS, Brazil
Correspondence to:

Faculdade de Medicina, UFRGS

Rua Ramiro Barcelos, 2400,

$2^{\circ}$ andar - 90035-003 - Porto Alegre

RS, Brazil

Ic-antunes@hotmail.com.

Received on June/9/2010 Accepted on Sept/9/2010

\begin{abstract}
Objective: Correlate shift work with body mass index (BMI), waist circumference, chronotype and depressive symptoms. Subjects and methods: This study comprising 14 shift workers and 13 day workers. Subjects were workers from the health area aged 25 to 60 years. Minor psychiatric disorders were accessed by Self Report Questionnaire (SRQ-20) and depressive symptoms by Beck Depression Inventory (BDI). Chronotype was accessed using Morningness-Eveningness Questionnaire (MEQ). Anthropometric measures were taken. Results: Shift workers presented higher BMI $(P=0.03)$ and waist circumference $(P=0.004)$ than day workers. Years on shift work were significantly correlated to waist circumference $(r=0.43 ; P=0.03)$ and age $(r=0.47 ; P=$ 0.02). Shift work was not correlated with depressive symptoms and chronotype. Conclusion: These results may suggest a role played by shift work on the development and/or the early clinic manifestations of metabolic disturbances, becoming a risk factor to metabolic syndrome. Arq Bras Endocrinol Metab. 2010;54(7):652-6
\end{abstract}

\section{Keywords}

Shift work; sleep-wake cycle; waist circumference; depressive symptoms; chronotype

\section{RESUMO}

Objetivo: Correlacionar o trabalho de turno com índice de massa corporal (IMC), circunferência abdominal, cronotipo e sintomas depressivos. Sujeitos e métodos: Amostra de 14 trabalhadores de turno e 13 diurnos, com idade entre 25 e 60 anos. Transtornos psiquiátricos menores foram aferidos pelo Self Report Questionnaire (SRQ-20), sintomas depressivos pelo inventário de Depressão de Beck (BDI) e o cronotipo pelo Morningness-Eveningness Questionnaire (MEQ). As medidas antropométricas foram mensuradas. Resultados: Trabalhadores de turno apresentaram maior IMC $(P=0,03)$ e circunferência abdominal $(P=0,004)$ quando comparados aos diurnos. 0 tempo de trabalho de turno foi correlacionado à circunferência abdominal $(r=0,43$; $P=0,03)$. Não houve correlação entre trabalho e sintomas depressivos e cronotipo. Conclusão: Os resultados podem sugerir que o trabalho de turno desempenhe um papel no desenvolvimento e/ou nas precoces manifestações clínicas de distúrbios metabólicos, tornando-se um fator de risco para a síndrome metabólica. Arq Bras Endocrinol Metab. 2010;54(7):652-6

Descritores

Trabalho de turno; ciclo sono-vigília; circunferência abdominal; sintomas depressivos; cronotipo

\section{INTRODUCTION}

$\mathrm{T}$ the major function of the circadian system is the internal cycling of physiological and metabolic events.
In fact, many physiological processes display day-night rhythms. The temporal organization of the human body has to be understood to appreciate the impact of night 
and shift work on humans. The circadian rhythms of individuals synchronize the environment through lightdark phase and social rhythm. In night-day alterations, such as in shift workers, alterations in social routine and/or meal times are described as desyncronization (1). Endogenous biological clocks improve the efficiency of biological systems, by allowing them to anticipate future constraints on major physiological systems and cell energy metabolism. The temporal organization of a given biological function can be impaired in its coordination with astronomical time or with other biological functions. There are also external conditions that influence biological clocks. This temporal organization is complex, and it is possible that also many medical disorders such as cardiovascular (2-4), metabolic $(2,5$ $7)$, psychiatric $(8,9)$ and sleep disorders (10) involve primary or secondary changes in biological clocks (11). Previous studies have demonstrated that risks increase according to exposure, such as hypertension, diabetes, coronary artery disease and weight gain $(12,13)$.

Some studies have demonstrated a relationship between shift work and metabolic alterations $(2,10,14,15)$. The constellation of metabolic abnormalities, called metabolic syndrome, includes glucose intolerance (impaired glucose tolerance, or impaired fasting glycemia), insulin resistance, central obesity, dyslipidemia, and hypertension, predisposing subjects to an increased risk of type 2 diabetes and cardiovascular diseases (15). The fact that shift workers present a chronically reversed sleep-wake cycle may be associated to the higher incidence of metabolic syndrome in this population $(2,16)$. Shift work related to circadian rhythmicity disruption, occur with alterations in one or more of the pathological components of the metabolic syndrome (17).

Also, Shift work is suggested to increase the risk of developing or aggravating mood disorders. That may be a consequence of alterations on rhythmic patterns in different levels $(8,18)$. They are also characterized by spontaneous or induced changes in endogenous rhythms, as in the case of shift work schedules and time of exposure to this inversion of phase. Another factor that may be related to the vulnerability to depression may be the individuals' differences in the preferences about their sleeping time, known as chronotype (19). Chronotype is partially determined by clock genes (19). Sleep impairment can be a common factor in mood disorders that could be aggravated by work environments.
The aim of the present study was to verify the correlation among shift work with waist circumference, body mass index (BMI), chronotype and depressive symptoms.

\section{SUBJECTS AND METHODS}

A total of 27 subjects, aged 25-60 years, were enrolled at this study. In the daily workers there 13 women enrolled and in the shift workers group, 14 subjects $($ men $=2)$ and (women $=12$ ). These subjects comprise a convenience sample that was selected among workers involved in the health area from Hospital de Clínicas de Porto Alegre RS, Brazil. All participants signed a written informed consent to be included into the study, which was approved by the Ethics Committee and performed in accordance to the guidelines proposed in the Declaration of Helsinki.

All subjects were asked about their work type/schedule, clinical history, and their life style. Since one of the inclusion criteria was to have at least 1 year of shift work, for the reason that constitutes latency for shift work to exert its effects. All subjects diagnosed with any metabolic disease or psychiatric disorder, pregnant women or with children less than 1 year, subjects under use of psychiatric, amphetamine and corticoid drugs were excluded from the study. In addition, shift workers (night workers) could not be employed or develop another regular activity, such as university students in the morning shift, neither on their rest days. Those submitted to current clinical treatment directed to lose weight or invasive procedures were also excluded.

Subjects answered Self-Report Questionnaire (SRQ$20)$ to identify minor psychiatric disorders and Beck Depressive Inventory (BDI) to assess the severity of depressive symptoms (20). The 21 - items assess cognitive, affective, somatic, and behavioral symptoms on a four-point scale. The total BDI is the sum of all items ranging from 0 to 63. We used a Beck Scores 0-9, 10$18,>18$ to indicate none, mild or moderate/severe symptoms, respectively.

To determine the phenotype related with morningness-eveningness dimension the self-reported questionnaire named Morningness Eveningness Questionnaire (MEQ) was used. It is an instrument constituted of 19 items. The score is the sum of the item and ranges from 16 to 86 , being the higher score to morningness.

Subjects underwent measurement of anthropometric parameters. The procedure was conducted in the early morning. Waist circumference was measured as the midway between the lower-rib margin and the su- 
perior anterior iliac spine. Additionally, BMI was calculated as $\mathrm{kg} / \mathrm{m}^{2}$ and was used as the index for relative weight. Overweight was defined as a BMI $\geq 24,9$ whereas obesity BMI $\geq 29,9$ according to World Health Organization (WHO) parameters. All measures were performed by one trained examiner blinded to the objective of the study, avoiding assessment bias.

Concerning the work schedule, the day sample worked from 08:00-17:00, whereas shift workers were engaged in regular 12-h night shifts (19:00-7:00). A self-report social-demographic questionnaire covering the characteristics of work and life style was performed before subjects underwent anthropometric evaluation and collected on this day.

The statistical analysis was performed using the SPSS 16 program for Windows software. Results are presented as median and percentiles for all parameters. Differences between shift workers and day workers were analyzed by non-parametric test for 2 independent samples. The statistical significance was defined as $\mathrm{P} \leq 0.05$ (Type I error). An error type II was estimated in $80 \%$. Correlations were verified using Pearson Correlation Test.

\section{RESULTS}

Table 1 shows the demographic characteristics. Shift workers presented higher BMI $(\mathrm{P}=0.03)$ and waist circumference $(\mathrm{P}=0.004)$ than the day workers. Moreover, a positive relationship was found between BMI and waist circumference $(\mathrm{r}=0.87 ; \mathrm{P}<0.001)$. A correlation between years on shift and waist circumference $(\mathrm{r}=0.43 ; \mathrm{P}=0.03)$ and age $(\mathrm{r}=0.47 ; \mathrm{P}=0.02)$ was shown (Table 2). However, we did not find correlation with years on shift and depressive symptoms or chronotype. Furthermore, chronotype was inversely correlated with SRQ-20 $(\mathrm{r}=-0.4 ; \mathrm{P}=0.04)$ i.e. eveningness phenotype presented higher levels in the SRQ.

Table 1. Demographic characteristics of daily and shift workers. Data are presented as median and percentiles. Non-parametric test for 2 independent samples

\begin{tabular}{|c|c|c|}
\hline & Daily workers & Shift workers \\
\hline Age (years) & $34.00(27.00-41.50)$ & $43.50(38.75-50.50)$ \\
\hline Body weight (kg) & $59.60(54.00-66.25)$ & $73.10(64.80-82.12)$ \\
\hline Height (m) & $1.62(1.57-1.73)$ & $1.63(1.58-1.65)$ \\
\hline BMl $\left(\mathrm{kg} / \mathrm{m}^{2}\right)$ & $23.07(20.70-25.04)$ & $29.22(24.68-32.05)^{\star}$ \\
\hline Waist circumference (cm) & $77.00(71.00-82.10)$ & $93.00(88.88-99.25)^{\star \star}$ \\
\hline
\end{tabular}

Table 2. Pearson correlation coefficients among years on shift work and waist circumference and BMI

\begin{tabular}{lc}
\hline & Years on shift work \\
\hline Waist circumference & $0.438^{\star}$ \\
BMI & 0.401 \\
Chronotype & -0.113 \\
Depressive symptoms & 0.267 \\
Minor psychiatric disorder & 0.089 \\
Age & $0.475^{*}$ \\
\hline
\end{tabular}

${ }^{*} \mathrm{P}<0.05$.

\section{DISCUSSION}

We observed a correlation between years on shift work and waist circumference. Besides this, shift workers presented higher BMI and waist circumference than day workers. These results may suggest a role played by shift work on the development and/or the early clinic manifestations of metabolic disturbances, becoming a risk factor to metabolic syndrome. The misalignment between the endogenous circadian system and the sleepwake cycle, promoted by shift work, might contribute to the clinical status of subjects suffering from a variety of metabolic disorders as showed in our study. These results seem to be supported and replied to by previous studies $(2,3,5,7,13,21-25)$.

BMI and waist circumference were also correlated. Shift workers presented a higher age; this could be a confounding variable, but we did not find correlation between age and BMI or waist circumference. Human rhythms are synchronized to diurnal activity by the environmental light-dark cycle and their social routine, then undergoing into phase readjustment when forced to adhere to a new sleep-wake pattern. In shift work, central and peripheral oscillators must adapt to a new rhythmicity imposed by the work schedule. It is necessary that some sleep-wake cycles adjust to the changed phase of the environmental synchronizer. It is known that even after a prolonged duration of time on shift, only a minority of night workers show phase adaptation of their circadian system to the nocturnal activity pattern. Even receiving daylight on the way home, shift workers face a problem originated by their labor journey regarding their meals which will be mostly taken at night, period where they are active. Therefore, we hypothesize that this internal misalignment associated with night eating and life style may induce profound effects on metabolic parameters, demonstrated by their increased BMI and waist circumference. It is known 
that the caloric intake of shift workers is very similar to that of day workers (26), however their metabolic efficiency may be impaired once major caloric intake is often at night (27). In addition, it is important to highlight that leptin and ghrelin, anorexin and orexin hormones, respectively, are secreted, as most hormones, in a circadian pattern (14,28-31). Light exposure at night may contribute to a decreased and/or delayed secretion of leptin, which usually occurs at night and has its acrophasis around midnight, further contributing to an enhanced hunger and food intake pattern. This leads to weight gain and visceral fat accumulation in the abdominal region which simultaneously with stress, job strain and psychosocial factors, predisposes shift workers to a cortisol hypersecretion, hyperstimulation from the hypothalamic-pituitary-adrenal axis leading the adipose tissue to produce even more fat tissue.

Regarding shift work and depressive symptoms, we did not find any correlation, although chronotype is correlated to minor psychiatric disorders in this study. Also, eveningness chronotype was correlated to minor psychiatric disorders. This finding is in accordance to previous studies from our group: the evening chronotype seems to be more susceptible, predisposing subjects with this phenotype to mood disorders (18). In a previous study, the author proposes that the effect of shift work on depressive symptoms is explained by the association between job characteristics and psychosocial factors, once this population also suffers from deprivation of their social life (8), however, in this study they did not analyze chronotype. Once chronotype was related to mental disorders, it is clear that in our study it did not exert an influence on shift work, independent from the stress demanded by this kind of labor journey.

In conclusion, we suggest a new model of shift work physiopathology, where chronotype is not associated to shift work, although chronotype was correlated to mental symptoms. In addition, we provide evidence that shift work is directly correlated to BMI and waist circumference. Further studies are necessary to clarify how shift work influences metabolic disturbances and what components of metabolism and biological oscillators are altered in shift workers.

Acknowledgments: The authors thank Alessandra Campos who helped at data collection and Post-Graduation Program in Medical Sciences, School of Medicine, Universidade Federal do Rio Grande do Sul (UFRGS), Porto Alegre, Brazil.

This work was supported by Fundo de Incentivo à Pesquisa e Eventos (FIPE) at Hospital de Clínicas de Porto Alegre, Brazil.
Disclosure: no potential conflict of interest relevant to this article was reported.

\section{REFERENCES}

1. Beersma DG, Gordijn MC. Circadian control of the sleep-wake cycle. Physiol Behav. 2007;90(2-3):190-5.

2. Biggi N, Consonni D, Galluzzo V, Sogliani M, Costa G. Metabolic syndrome in permanent night workers. Chronobiol Int. 2008;25(2):443-54.

3. Scheer FA, Hilton MF, Mantzoros CS, Shea SA. Adverse metabolic and cardiovascular consequences of circadian misalignment. Proc Natl Acad Sci U S A. 2009;106(11):4453-8.

4. Sookoian S, Pirola CJ. Shift work and subclinical atherosclerosis: recommendations for fatty liver disease detection. Atherosclerosis. 2009;207:346-7.

5. Conway PM, Campanini P, Sartori S, Dotti R, Costa G. Main and interactive effects of shiftwork, age and work stress on health in an Italian sample of healthcare workers. Appl Ergon. 2008;39(5):630-9.

6. Morgan L, Hampton S, Gibbs M, Arendt J. Circadian aspects of postprandial metabolism. Chronobiol Int. 2003;20(5):795-808.

7. Sookoian S, Gemma C, Fernandez Gianotti T, Burgueno A, Alvarez A, Gonzalez CD, et al. Effects of rotating shift work on biomarkers of metabolic syndrome and inflammation. J Intern Med. 2007;261(3):285-92.

8. Woo JM, Postolache TT. The impact of work environment on mood disorders and suicide: evidence and implications. Int J Disabil Hum Dev. 2008;7(2):185-200.

9. YamadaY, Kameda M, NoborisakaY, Suzuki H, Honda M, Yamada S. Excessive fatigue and weight gain among cleanroom workers after changing from an 8-hour to a 12-hour shift. Scand J Work Environ Health. 2001;27(5):318-26.

10. Wolk R, Somers VK. Sleep and the metabolic syndrome. Exp Physiol. 2007;92(1):67-78.

11. Lamont EW, Legault-Coutu D, Cermakian N, Boivin DB. The role of circadian clock genes in mental disorders. Dialogues Clin Neurosci. 2007;9(3):333-42.

12. MorikawaY, Nakagawa $\mathrm{H}$, Miura $\mathrm{K}$, SoyamaY, Ishizaki M, KidoT, et al. Shift work and the risk of diabetes mellitus among Japanese male factory workers. Scand J Work Environ Health. 2005;31(3):179-83.

13. Morikawa $Y$, Nakagawa $H$, Miura $K$, Soyama $Y$, Ishizaki M, Kido T, et al. Effect of shift work on body mass index and metabolic parameters. Scand J Work Environ Health. 2007;33(1):45-50.

14. Shea SA, Hilton MF, Orlova C, Ayers RT, Mantzoros CS. Independent circadian and sleep/wake regulation of adipokines and glucose in humans. J Clin Endocrinol Metab. 2005;90(5):2537-44.

15. Executive Summary ofThe Third Report of The National Cholesterol Education Program (NCEP) Expert Panel on Detection, Evaluation, And Treatment of High Blood Cholesterol In Adults (Adult Treatment Panel III). JAMA. 2001;285(19):2486-97.

16. Holmback U, Forslund A, Lowden A, Forslund J, Akerstedt T, Lennernas $M$, et al. Endocrine responses to nocturnal eating--possible implications for night work. Eur J Nutr. 2003;42(2):75-83.

17. Tanofsky-Kraff M, Yanovski SZ. Eating disorder or disordered eating? Non-normative eating patterns in obese individuals. Obes Res. 2004;12(9):1361-6.

18. Hidalgo MP, CaumoW, Posser M, Coccaro SB, Camozzato AL, Chaves ML. Relationship between depressive mood and chronotype in healthy subjects. Psychiatry Clin Neurosci. 2009;63(3):283-90.

19. RoennebergT, Merrow M. The network of time: understanding the molecular circadian system. Curr Biol. 2003;13(5):R198-207. 
20. Gorenstein C, Andrade L, Vieira Filho AH, Tung TC, Artes R. Psychometric properties of the Portuguese version of the Beck Depression Inventory on Brazilian college students. J Clin Psychol. 1999;55(5):553-62.

21. Di Lorenzo L, De Pergola G, Zocchetti C, L'Abbate N, Basso A, Pannacciulli $N$, et al. Effect of shift work on body mass index: results of a study performed in 319 glucose-tolerant men working in a Southern Italian industry. Int $\mathrm{J}$ Obes Relat Metab Disord. 2003;27(11):1353-8.

22. Copertaro A, Bracci M, Barbaresi M, Santarelli L. [Role of waist circumference in the diagnosis of metabolic syndrome and assessment of cardiovascular risk in shift workers]. Med Lav. 2008;99(6):444-53.

23. Esquirol Y, Bongard V, Mabile L, Jonnier B, Soulat JM, Perret B. Shift work and metabolic syndrome: respective impacts of job strain, physical activity, and dietary rhythms. Chronobiol Int. 2009;26(3):544-59.

24. Garaulet M, Madrid JA. Chronobiology, genetics and metabolic syndrome. Curr Opin Lipidol. 2009;20(2):127-34.

25. Lin YC, HsiaoTJ, Chen PC. Persistent rotating shift-work exposure accelerates development of metabolic syndrome among middle- aged female employees: a five-year follow-up. Chronobiol Int. 2009;26(4):740-55.

26. MorikawaY, Miura K, Sasaki S, Yoshita K, Yoneyama S, Sakurai M, et al. Evaluation of the effects of shift work on nutrient intake: a cross-sectional study. J Occup Health. 2008;50(3):270-8.

27. Romon M, Edme JL, Boulenguez C, Lescroart JL, Frimat P. Circadian variation of diet-induced thermogenesis. Am J Clin Nutr. 1993;57(4):476-80.

28. Motivala SJ, Tomiyama AJ, Ziegler M, Khandrika S, Irwin MR. Nocturnal levels of ghrelin and leptin and sleep in chronic insomnia. Psychoneuroendocrinology. 2009;34(4):540-5.

29. Yang S, Liu A, Weidenhammer A, Cooksey RC, McClain D, Kim $\mathrm{MK}$, et al. The role of mPer2 clock gene in glucocorticoid and feeding rhythms. Endocrinology. 2009;150(5):2153-60.

30. Inyushkin AN, Bhumbra GS, Dyball RE. Leptin modulates spike coding in the rat suprachiasmatic nucleus. J Neuroendocrinol. 2009;21(8):705-14.

31. Ptitsyn AA, Gimble JM. Analysis of circadian pattern reveals tissue-specific alternative transcription in leptin signaling pathway. BMC Bioinformatics. 2007;8 Suppl 7:S15. 